\title{
The Role of Batteries in High Power Charging Infrastructure
}

\author{
Karin Jahn \\ Department of Electromobility \\ OE Energy System Analysis \\ Fraunhofer Institute for Manufacturing Technology and \\ Advanced Materials IFAM \\ Bremen, Germany \\ karin.jahn@ifam.fraunhofer.de
}

\author{
Carl-Friedrich Klinck \\ Near-net-shaping Production Technologies \\ University of Bremen \\ Bremen, Germany \\ klinck@uni-bremen.de
}

\begin{abstract}
The project "Cities in Charge" aims at deploying high-power DC and AC charging infrastructure for electric vehicles in twelve different regions in Germany. Foci of the project are the acceleration of the expansion of electro mobility in the target areas, the investigation of interaction of vehicle owners with the charging technology and the analysis of the influence on the distribution network. In this context, Fraunhofer IFAM investigates the possible contribution of battery storage systems for grid assisting charging.
\end{abstract}

From more than 190 planned charging sites those were identified where the grid capacity is limited, and the use of batteries is an alternative to grid reinforcement. For the dimensioning of the battery, it is necessary either to know the charging load or to estimate the load that results from the expected utilization of the charging stations as realistically as possible.

As construction of the charging infrastructure did not begin until 2019, real usage data were not available before December 2019. Therefore, Fraunhofer IFAM has developed a probabilistic simulation model to determine the utilization of charging stations. The simulation results are used in a second model assessing the load flows of the charging station. On the basis of these load flows, recommendations for the dimensioning of the batteries are derived. First results show that maximum load occurs less often than assumed and that use of batteries might be the preferable option if the desired availability of charging may be slightly lower than $100 \%$.

Keywords - Electric vehicle, High power charging, Battery, Simulation analysis, Charging load, Charging stations, Electric grid

\section{INTRODUCTION}

In order to achieve the climate protection goals of the Federal Republic of Germany, the climate protection program aims at reducing emissions from the transport sector by at least $40 \%$ by 2030 compared to 1990 . In this context, the expansion of electromobility plays a decisive role. Due to the provision of subsidies and against the background of the discussion about the emissions of diesel cars, the number of electric vehicles in Germany has recently increased significantly [1]. At the same time, the charging infrastructure was massively expanded from 7.400 public and semi-public charging points in 2016 to 23.840 in 2019 (see Fig. 1).

In addition, the DC charging infrastructure was developed continuously. Thus, in mid-2019, $15 \%$ of the charging points were fast chargers [2]. They allow significantly shorter charging times than conventional AC chargers and improve the suitability of electric cars for everyday use and their broader acceptance.

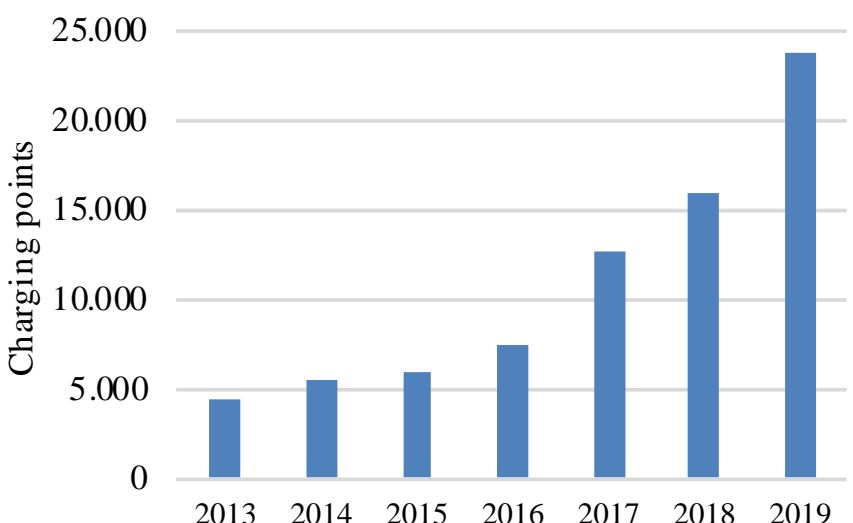

Fig 1. Public and semi-public charging points in Germany 2013 - 2019 [3]

However, the integration of high-power charging stations represents a challenge to the grid. Often, the grid capacity is not sufficient to supply the charging station, so that grid expansion is required [4]. For this reason, measures for the stabilization of the grid and the prevention of grid expansion are becoming more and more important in the future. Several charging stations already have simple tools for load control and the first models with integrated batteries are available on the market [5], [6], [7].

Within the project "Cities in Charge", Fraunhofer IFAM investigates which contribution battery storage can make to overcoming grid bottlenecks and to making the installation of charging infrastructure economically feasible. Since the first charging stations with flywheels for grid support have been installed recently in other projects, this technology will also be briefly examined in the context of this project. For this purpose, IFAM has selected twelve locations from more than 
190 sites where high-power charging infrastructure will be built as part of the project (see Fig. 2). In the selected locations, the network capacity is limited, and expansion of the network might be necessary.

For a reliable evaluation of the expansion requirement, an estimation of the utilization of the charging station is necessary. As there is hardly any information on real utilization profiles of high-power charging stations available so far, a probabilistic simulation model was developed to investigate the future utilization of the charging infrastructure at these sites.

In a first step, the maximum load that can be expected at the respective charging stations is determined. At that point possible limitations of the network capacities are not taken into account. In the second step, it is analyzed how many of the charging processes cannot be carried out as desired if the grid capacity is limited to a certain value. Based on these results, the third step finally examines whether the use of storage devices is necessary and, if so, how the storage should be dimensioned.

\section{SELECTION OF SITES FOR IMPLEMENTATION OF BATTERIES}

Within the project "Cities in Charge", over 1.100 charging points will be installed in more than 30 cities and in surrounding areas in eleven federal states of Germany until 2022. The majority of these charging stations will be equipped with two DC-charging points and at least one AC-charging point. More than one third will be DC-charging points with a power of $100 \mathrm{~kW}$ to $150 \mathrm{~kW}$. The stations are being installed by Comfort Charge $\mathrm{GmbH}$, a subsidiary of Telekom AG, and will be placed on Telekom's own properties. Those will be accessible to the general public. Additionally, in some locations charging points for employees will be provided.

Medium voltage connections are available at all planned locations, most of them with considerable reserve power. Fraunhofer IFAM has identified those locations where the reserve is insufficient to cover the station's power requirements. Twelve sites were selected for further investigation concerning the option of installing batteries. The following selection criteria were applied:

- Amount of lack of reserve power

- Type of settlement at the station's location

- Distribution of locations in Germany

The main criterion is the lack of reserve power. It is defined as the difference between the available reserve power and $75 \%$ of the maximum charging power, i.e. when all charging points were used simultaneously with maximum power. The type of settlement is relevant in so far as it has an influence on the utilization of the charging stations. For example, stations in commercial areas will be frequented differently than those in residential areas. A spatial distribution is also aimed at, as the regions differ in terms of socio-economic data. This could result in different densities and types of electric vehicles und lead to diverse utilization of charging stations.

The twelve selected locations represent four types of settlement, and they are located in nine different German countries. Fig. 2 shows the locations selected for further analysis.

For all selected locations, detailed information was collected concerning the space available for safe battery installation and its distance to the charging station, distance between charging station and the grid, potential for installation of PV systems etc. These data are relevant for the estimation of the costs of the implementation of batteries and the comparison with the costs for grid enhancement, which is carried out later in the course of the project.

\section{ELABORATION OF LOAD PROFILES}

Whether it makes (economically) sense to set up stationary battery storage units at the charging stations depends largely on the individual utilization of the stations. If a station is used only frequently or vehicles are mostly charged at low power levels, generally a smaller battery size is advisable than for those stations that are used intensively or where vehicles are charged at high power levels.

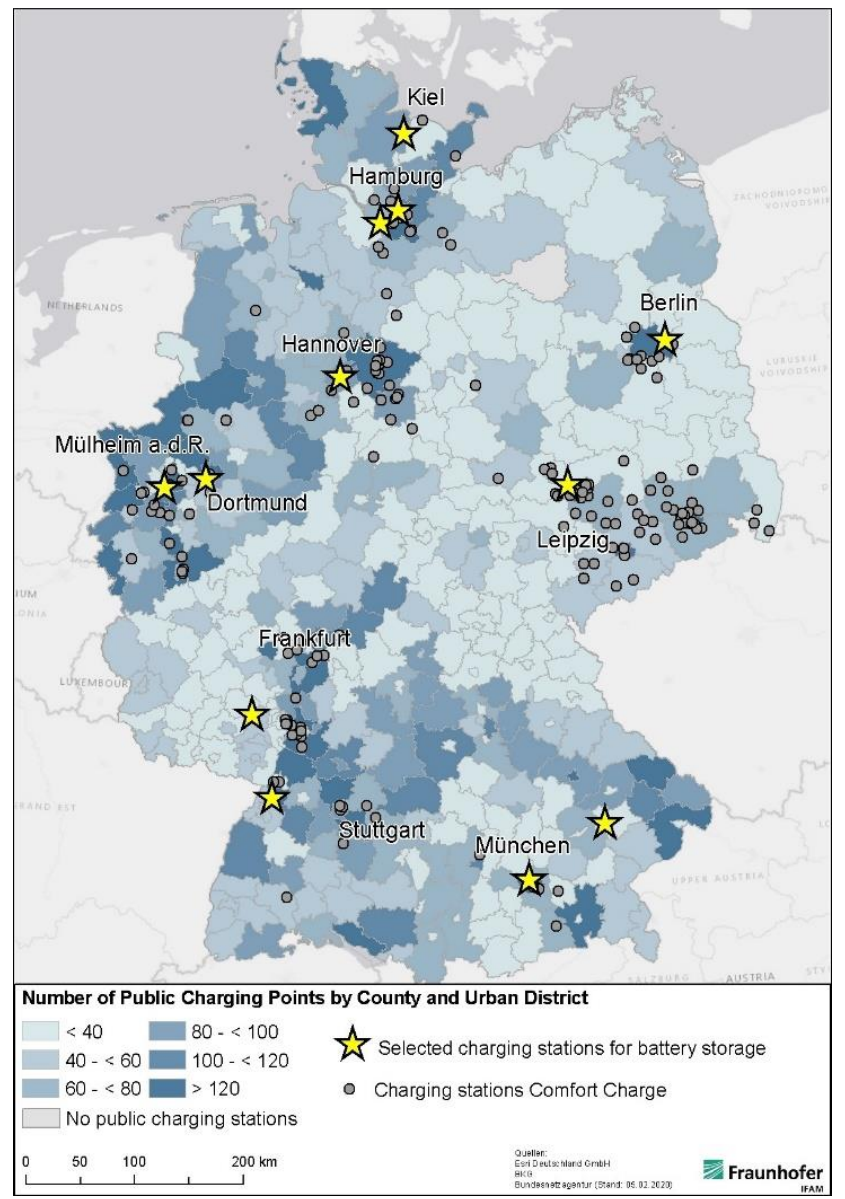

Fig. 2. Selected sites for further Investigation

However, the utilization of a planned station is usually not known in advance. Therefore, a probabilistic load profile generator is being developed as part of the project. With this generator artificial load profiles can be generated for not yet constructed sites - based on a multitude of input data. In the first step, limited grid connection services are deliberately not taken into account, but rather the "wishes" of the users. From these data, further analyses are carried out to determine the 
consequences of limited grid capacity and the installation of battery storage.

In the following, the methodology for creating the artificial loading profiles and the derivation of the required input data are briefly discussed. Subsequently, the procedure for storage dimensioning for different fictitious locations is presented.

\section{A. Methodology}

The simulation software allows the determination of the load of the desired charging processes of any charging location for any period of time (e.g. one year) in any temporal resolution (e.g. one minute). Random decisions are made for each charging point of the charging station in each time unit (see Fig. 3).

If a car has already been connected in a previous time unit, a decision is made whether the departure time previously determined for this vehicle has been reached. If this is the case, the corresponding charging process is terminated, and the charging point is again available for other vehicles. If the parking time is not yet reached, the vehicle remains connected. The charging of a connected vehicle takes into account the maximum charging capacity of the charging point as well as that of the vehicle's battery (depending on the state of charge (SoC)).

In case that the charging point is available, a randomized decision is taken whether a vehicle starts charging in this time unit or not. If charging starts, the vehicle class, the charge level at the beginning of the charging process and the parking time will again be determined randomly (based on the assumptions in the following section B). It is important to note here that it is not the loading time but the parking time that is determined. Thus, the case that vehicles park longer than they need to be fully charged and "block" the charging point can be considered. In Fig. 3 the structure of the described simulation process is summarized.

\section{B. Input and assumptions}

The data and the assumptions used in the simulation are based on a variety of real loading data recorded at locations within the project. In total, more than 3.500 charging processes were recorded in the second half of 2019 at stations of Comfort Charge. 124 charging processes took less than 60 seconds and were therefore not considered for the evaluations.

The dimensioning of the battery in chapter IV is carried out exemplarily for three types of settlement: "rural area", "industrial estate" and for a location not specified in more detail (average values of all locations - referred to as "general location"). Therefore, a differentiation between these three settlement types is already made for some of the input data.

Assumptions on arrival frequencies are particularly relevant. They depend on the day of the week, on the time of day, on the vehicle classes and thus on technical data of the electric vehicles, on the charge levels at the start of charging, and on parking time.

\section{1) Arrival frequencies}

Fig. 4 shows the average arrival frequencies for one week for the three site types considered. The arrival frequencies at a rural location are very similar to those at the general location.

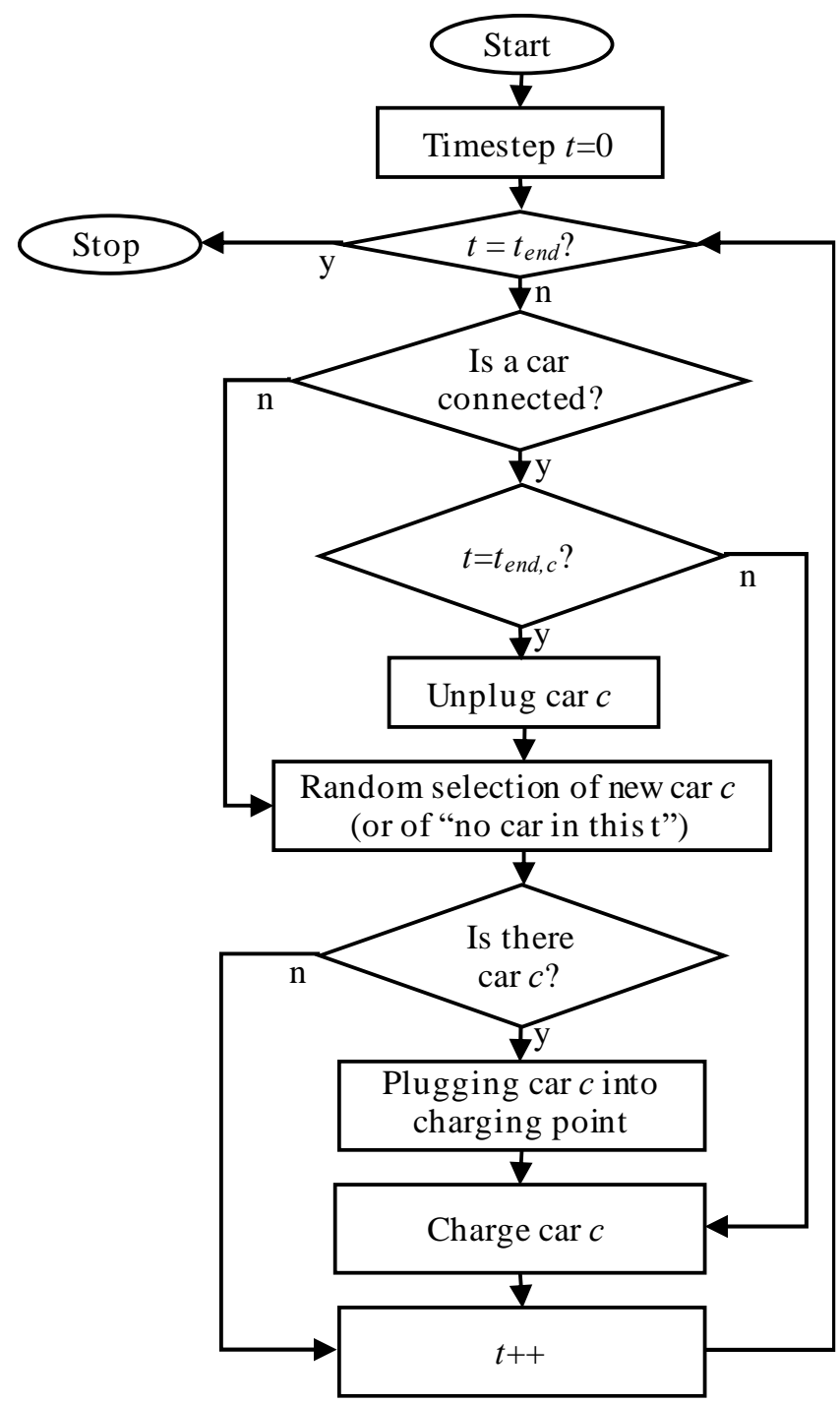

Fig. 3. Flow chart for the simulation of charging processes (of one charging point of a charging station) 


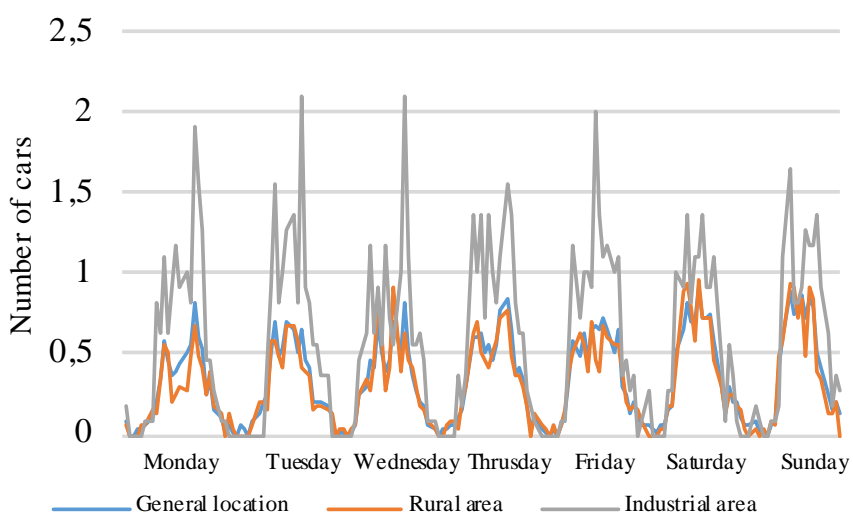

Fig. 4. Average number of charging processes per hour for one week

At a location in an industrial estate, however, considerably more vehicles are expected. Furthermore, it is noticeable that the frequencies at weekends are even higher than on weekdays at the rural location and the general location, whereas the opposite is observed for a location in the industrial area.

2) Distribution of vehicle categories and technical data of the vehicle

Four vehicle classes are taken into account: XS, S, M and

L. The categories were selected by a project partner and defined with regard to their technical data [8].

TABLE 1. ClassES OF ELECTRIC VEHICLES AND CHARGING POWER

\begin{tabular}{|l|c|c|c|c|}
\hline Vehicle class & XS & S & M & L \\
\hline Capacity [kWh] & 20 & 40 & 50 & 80 \\
\hline Max. charging & 11,22, & 11,22, & 43 & 43 \\
power AC [kW] & 43 & 43 & & \\
\hline Max. charging & - & 50 & 50, & 50, \\
power DC [kW] & & & 100 & 100, \\
& & & & 150 \\
\hline
\end{tabular}

Vehicle category XS includes mini cars, small and compact cars belong to the $\mathrm{S}$ class, the $\mathrm{M}$ class includes midrange cars and vans, and the L class includes luxury cars, sports cars and SUVs. The technical specifications of the vehicles are listed in Tab. 1. A maximum charging power is assumed for each vehicle. Due to the fact that different vehicles from the same vehicle class have different maximum charging powers, a further distinction is made. It is assumed that vehicle class $\mathrm{XS}$, for example, includes vehicles with a maximum charging power of $11 \mathrm{~kW}, 22 \mathrm{~kW}$ and $43 \mathrm{~kW}$ (with equally distributed probability of occurrence). To take into account charging losses, a loading efficiency of $85 \%$ was generally assumed.

The percentage of vehicle classes in the current stock of electric vehicles is shown in the following Fig. 5.

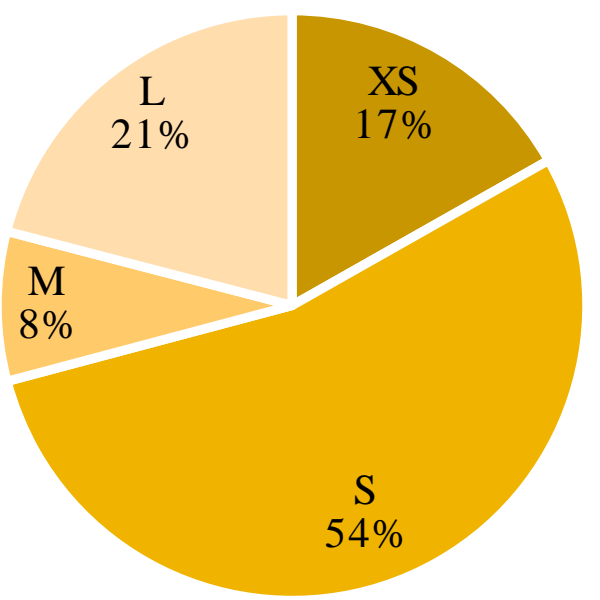

Fig. 5. Percentage of vehicle classes in the current stock of electric vehicles

3) State of charge at the start of the charging

In addition, the simulation took into account that the charging performance also depends on the state of charge of the battery. It is assumed that up to a SoC of $80 \%$ the charging power stays at the maximum value and then decreases linearly to $0 \mathrm{~kW}$ at an SoC of $100 \%$ (see Fig. 6).

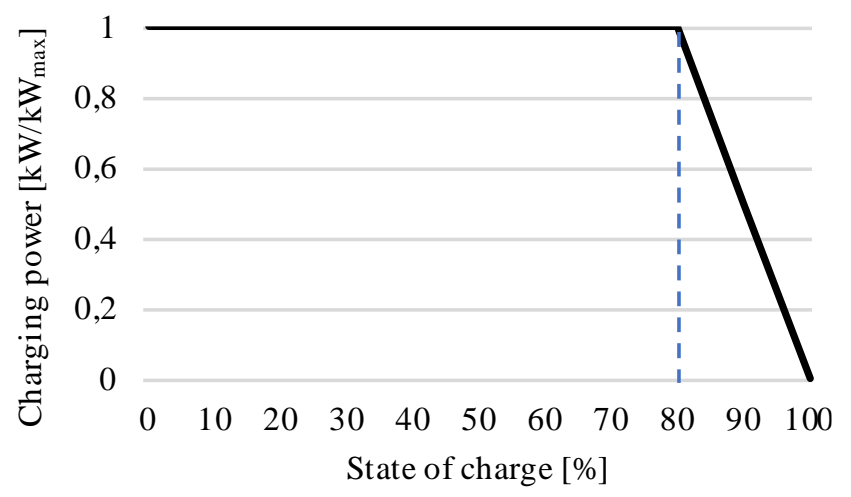

Fig. 6. Normalized charging power depending on the SoC

The distribution of the charge level of the vehicle's battery at the start of the charging process is another input parameter for the simulation. An analysis of the real charge data delivered the distribution shown in Fig. 7.

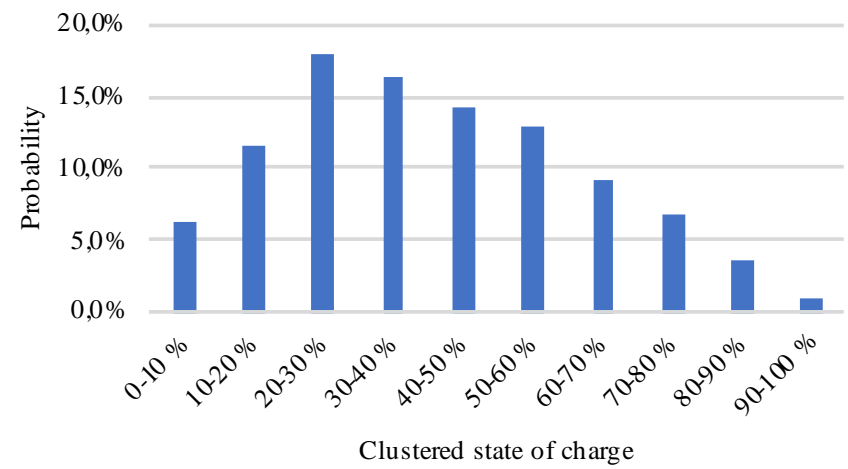

Fig. 7. SoC at the start of charging 
It should be noted that up to now SoC values are only available for some of the charging processes at the CCS connections which are being constructed within the project. However, a comparison with data from project partners shows that the values determined here are very valid [9].

\section{4) Parking time}

For the prediction of the utilization of the charging station, assumptions about the parking time are necessary. In contrast to the charging duration, the parking duration also takes into account those periods during which vehicles are already fully charged but block the charging point.

The analysis of the charging data showed that the parking durations differ significantly for the different connector types. The probabilities for the parking duration are shown in Fig. $8-11$. It is obvious that the charging processes at type 2 plug and type 2 socket take significantly longer than those at CCS and CHAdeMO.

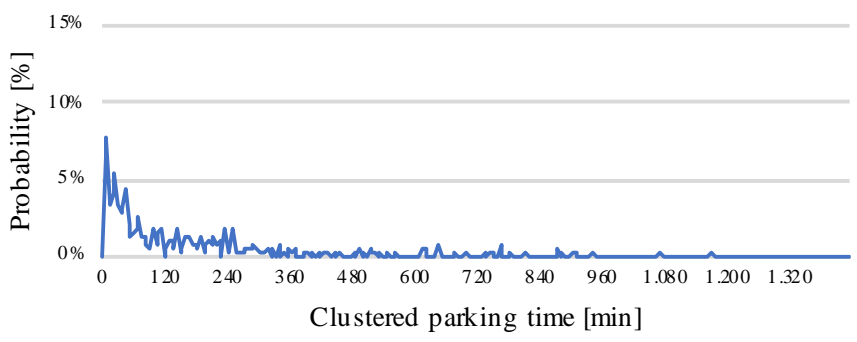

Fig. 8. Clustered parking time at type 2 plug ( 0 min: parking time between 0 and 5 minutes)

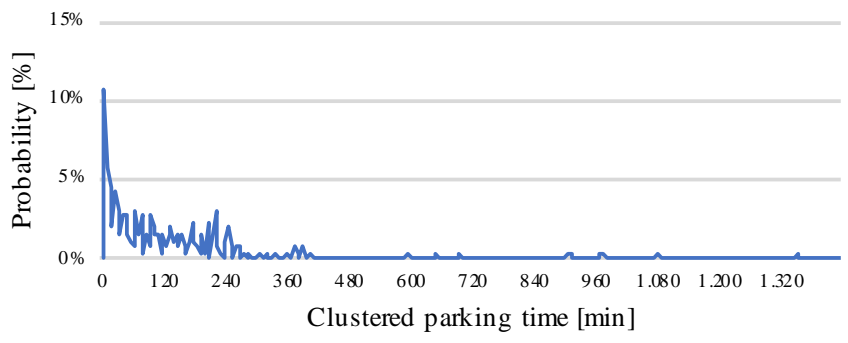

Fig. 9. Clustered parking time at type 2 socket

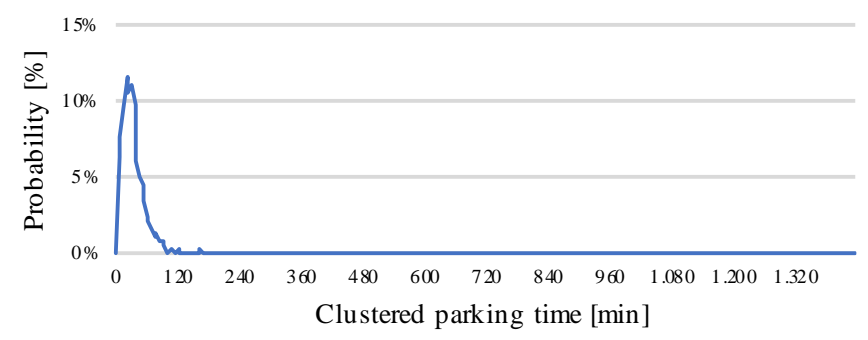

Fig. 10. Clustered parking time at CCS

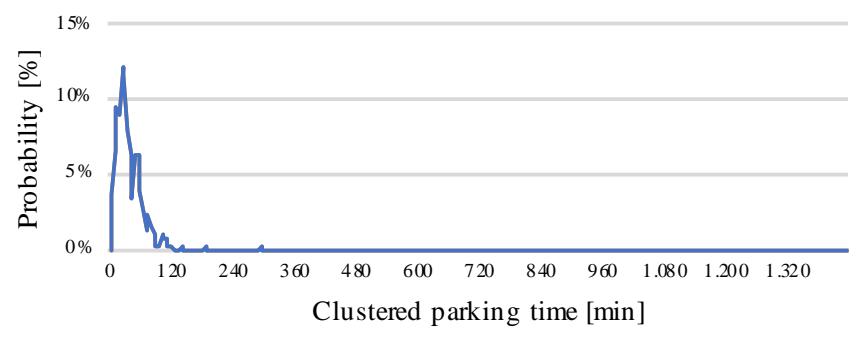

Fig. 11. Clustered parking time at CHAdeMO

\section{Charging curves}

With the algorithm presented in section $\mathrm{A}$ and the assumptions listed in section $\mathrm{B}$, random individual charging profiles were generated for each of the three settlement types ("general location", "rural area" and "industrial area"). These profiles are the basis for the battery dimensioning carried out in the following chapter.

As an example, a fictitious charging station in rural areas is considered here, which has the following charging points:

- $\quad$ Type 2 plug with max. $43 \mathrm{~kW}$

- Type 2 socket with max. $22 \mathrm{~kW}$

- $\quad$ CCS with max. $150 \mathrm{~kW}$

- $\quad$ CHAdeMO with max. $63 \mathrm{~kW}$

A load profile for one week of this station generated with the probabilistic load profile generator and based on the above assumptions is shown in Fig. 12.

At this location, a capacity of more than $200 \mathrm{~kW}$ is required only three times during this week. At the same time, it is also evident that the majority of charging processes takes place below $100 \mathrm{~kW}$. Comparisons with real charging data show that the predictions partly reflect reality very well, but partly also predict average energy requirements that are too high. One reason for this difference is fact that the load profile generator so far only considers pure electric vehicles and no plug-in hybrid vehicles. Including also these vehicles would result in lower average energy quantities per charging process due to the smaller battery capacity of plug-in hybrid vehicles. For this reason, this aspect will be taken into account in the further development of the load profile generator.

\section{DIMENSIONING OF THE BATTERY STORAGE}

The decision whether a storage - stationary battery or flywheel storage - is viable at a specific location depends on a variety of conditions. First, the maximum grid capacity must be taken into account: it determines the power that is provided for the charging station at an individual location. If the capacity of the charging station is higher than the available grid capacity, stationary storage systems could help to avoid grid expansion and the associated high investment costs. Furthermore, buffer storage systems can also be used to reduce the maximum supply peak. That can induce large cost savings in the annual power charge. This aspect is currently not yet taken into account but will be implemented in the future.

The second point to consider is the so-called "availability rate": this rate indicates the percentage of time units during 
which the required charging services must be fully provided. For instance, an availability rate of $95 \%$ means that the charging capacity may only be reduced in a maximum of $5 \%$ of the time units in which at least one vehicle is connected.

An availability rate of less than $100 \%$ can avoid that single above-average charging processes lead to high battery dimensions.

\section{A. Simulation of energy flows}

A second simulation software was developed in order to dimension the electricity storage units based on the probabilistic load profiles. With this software, a certain period of time can be simulated with a certain temporal resolution. Thus, one can examine how electricity storage devices can support the grid during charging processes for any location with limited grid connection capacity.

The following assumptions are made and implemented within the simulation software:

- If the power required for charging is less than the maximum grid capacity, the vehicles are charged from the grid.

- If the required power is higher than the grid capacity, the electricity storage is discharged to cover the difference. The maximum discharge capacity of the storage is taken into account.

- If the grid capacity is not fully utilized and the SoC of the stationary storage is less than $100 \%$, the storage is charged from the grid. The maximum grid capacity and the maximum charging power of the storage are taken into account.

Important technical data of the three storage types considered in the simulation are listed in Tab. 2.

TABLE 2. TECHNICAL DATA OF LEAD-ACID BATTERIES, LITHIUM-ION BATTERIES AND FLYWHEELS

\begin{tabular}{|l|c|c|c|}
\hline $\begin{array}{l}\text { Technical } \\
\text { data }\end{array}$ & $\begin{array}{c}\text { Lead-acid } \\
{[\mathbf{1 0}]}\end{array}$ & Li-ion [10] & $\begin{array}{c}\text { Flywheel } \\
{[11],[12]}\end{array}$ \\
\hline $\begin{array}{l}\text { Energy } \\
\text { density }\end{array}$ & $50-75 \mathrm{Wh} / \mathrm{l}$ & $200-350 \mathrm{Wh} / \mathrm{l}$ & $\begin{array}{c}70-100 \\
\mathrm{Wh} / \mathrm{kg}\end{array}$ \\
\hline $\begin{array}{l}\text { System } \\
\text { efficiency }\end{array}$ & $70-75 \%$ & $80-85 \%$ & $90 \%$ \\
\hline $\begin{array}{l}\text { Depth of } \\
\text { discharge }\end{array}$ & $70 \%$ & $100 \%$ & $100 \%$ \\
\hline
\end{tabular}

$$
250,0
$$

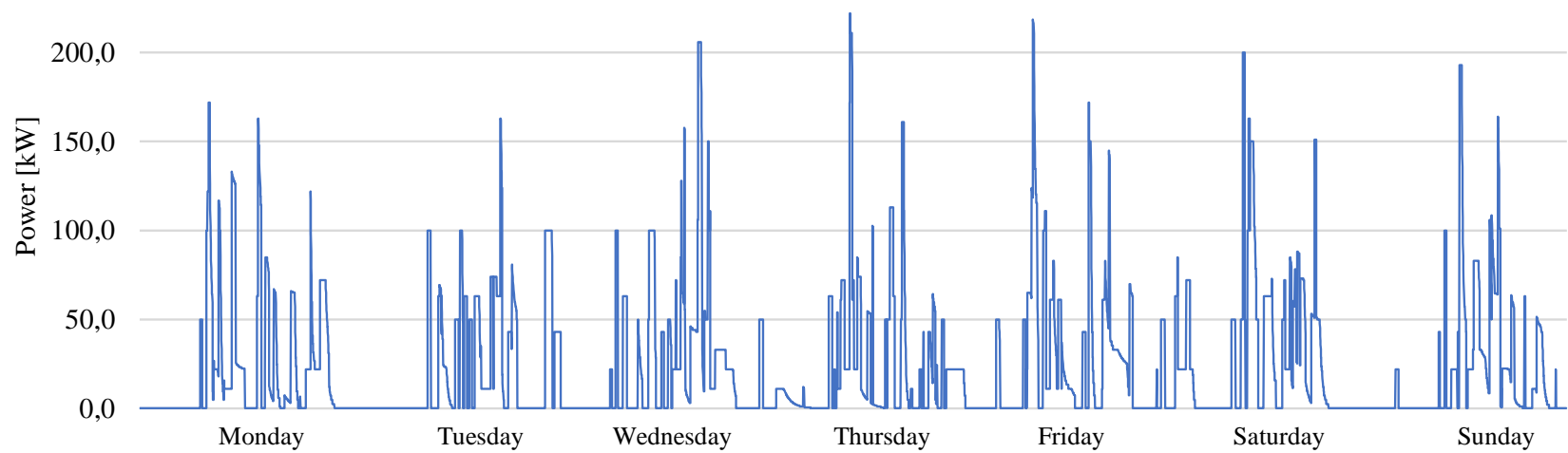

Fig. 12. Load profile for charging station in "rural area" (sum of all four charging points)

\section{B. Exemplary results}

\section{1) Lithium-ionen-batteries}

A charging station planned at a rural location with a limited grid capacity of $80 \mathrm{~kW}$ would only have an availability rate of $84 \%$ without the additional installation of a buffer storage and without grid expansion and at the utilization rate presented in Chapter III. This rate could be increased to almost $100 \%$ by installing a buffer storage (see Fig. 13). For an availability rate of $95 \%$, a stationary lithium-ion battery with a capacity of $46 \mathrm{kWh}$ would be required. The situation is very similar for the general site: here an availability rate of $95 \%$ could be also achieved with a lithium-ion battery with a capacity of at least $46 \mathrm{kWh}$.

In contrast, the capacity of a battery in an industrial area must be at least $74 \mathrm{kWh}$ to reach the availability rate of $95 \%$.

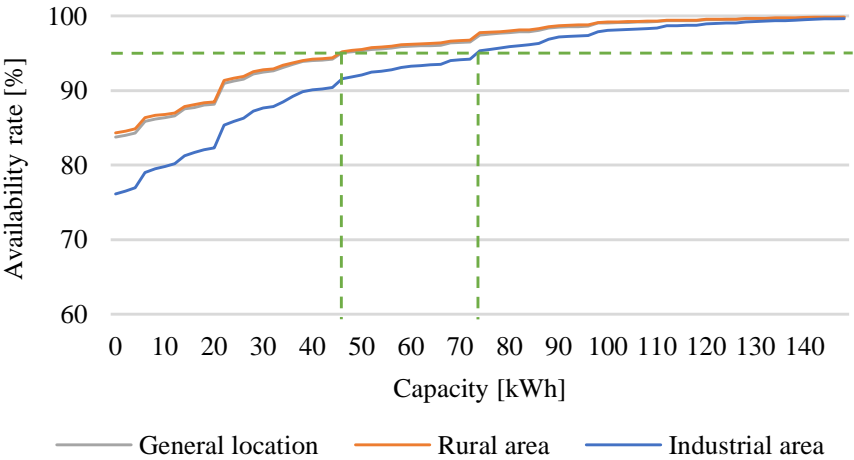

Fig. 13. Availability rate versus capacity of lithium-ion-battery

\section{2) Lead-acid batteries}

If classic lead-acid batteries are used instead of lithium-ion batteries, comparatively much larger battery capacities are required. This is particularly due to the fact that lead-acid batteries have significantly lower charging and discharging capacities than 
lithium-ion batteries - C-rate (quotient of power and capacity) of 0,2 instead of 1 for lithium-ion-battery. In applications where the performance and not the capacity of the battery is decisive, the battery capacity must be clearly oversized in order to achieve the required power performance. The simulations have shown that for an availability rate of $95 \%$, lead-acid batteries with a usable capacity of about $225 \mathrm{kWh}$ (rural area and all locations) or $370 \mathrm{kWh}$ (industrial area) would be necessary.

\section{3) Flywheel storage}

Flywheel storage systems have the particular advantage that their charging and discharging power is significantly higher compared to their capacity, i.e. they have a very high C-rate. The C-rate of conventional flywheels is in the range of about 30 , that of high-speed flywheel accumulators amounts to about 10 to 1.000 [12].

In addition, the raw materials used for flywheel storages are not critical, and their production is less energy-intensive than that of lithium-ion batteries [11]. Usually, steel is used for conventional flywheels and carbon or glass fiber composites are used as rotor materials for high-speed flywheels [13].

The first results show that for an availability rate of $95 \%$, the capacity of a flywheel storage with $30 \mathrm{C}$ should be at least $12 \mathrm{kWh}$ for rural areas, minimum $13 \mathrm{kWh}$ for a general location and at least $25 \mathrm{kWh}$ in industrial (see Fig. 14).

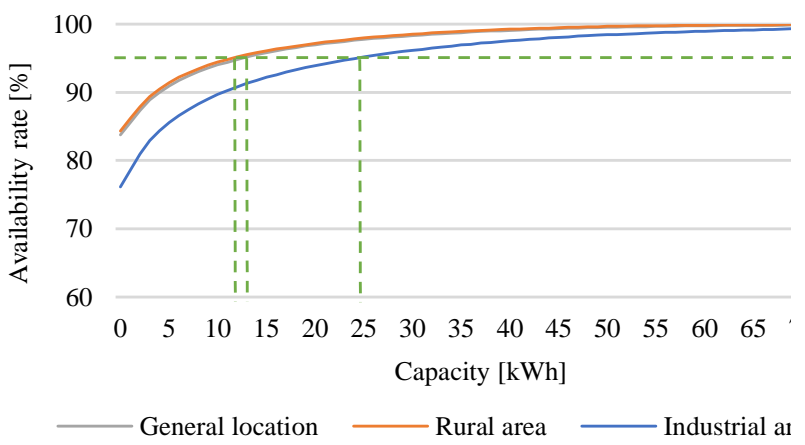

Fig. 14. Availability rate versus capacity of flywheel

It is evident that the capacity of the flywheel storage is only about $2 / 3$ less than that of Li-ion batteries despite the fact that its C-rate is 30 times that of Li-ion batteries. Therefore, it can be deduced that the capacity is the decisive factor for the dimensioning of flywheel storage systems, whereas charging and discharging power is the decisive factor for electrochemical storage systems. The power of flywheel storage systems would thus be clearly overdimensioned and would not be fully used at charging stations.
With the approach presented here, it is possible to analyze the expected utilization of charging stations already during the planning phase. It provides insights whether a storage facility could be useful to avoid limitations due to restrictions in grid capacity and ensure the desired availability rates of the charging station. Thus, with the methodology presented a decision-making basis is available for individually sites to estimate whether the investment in storage facilities is a reasonable alternative compared to a grid expansion.

\section{SUMMARY AND OUTLOOK}

A methodology is presented, that allows the prediction of the expected utilization of charging stations already in the planning phase. For this purpose, a probabilistic load profile generator has been developed, which generates randomly based load profiles.

Based on these load profiles, it is investigated whether storages are a viable alternative to grid enhancement at charging sites with limited grid capacity and, if so, how they should be dimensioned.

So far, the focus has been on achieving a high availability rate of the station of $95 \%$. It is always assumed that the available grid connection can be fully utilized. In reality, however, it can be reasonable not to fully utilize an existing grid connection, as this could reduce the annual service charge. In future the simulation software will be expanded to include a profitability analysis, which takes into account not only the service charge but also, for example, the investment and maintenance costs of the storage facilities and the maximum number of charging cycles of the battery. In addition, plug-in hybrids will be considered in the load profile generator.

Furthermore, it is planned to take into account sitespecific factors such as the average number of electric vehicles per 1000 inhabitants and the number of charging points per 1000 electric vehicles, as it can be assumed that these also have a significant influence on the capacity utilization of the charging stations. The further development and validation will also include results from the evaluation of future charging data from the project.

\section{ACKNOWLEDGMENT}

This project on which this report is based was funded by the Federal Ministry of Education and Research under the funding number 01MZ18005B. Responsibility for the contend of this publication lies with the authors.

\section{REFERENCES}

[1] Kraftfahrt-Bundesamt, "Bestand an Pkw in den Jahren 2010 bis 2019 nach ausgewählten Kraftstoffarten" ("Stock of cars in the years 2010 to 2019 according to selected type of fuels") 
[Online].

Available: https://www.kba.de/DE/Statistik/Fahrzeuge/Bestand/Umwelt/ 2019_b_umwelt_z.html?nn=663524.

[2] Bundesnetzagentur für Elektrizität, Gas, Telekommunikation, Post und Eisenbahnen, "Monitoringbericht 2019“, ("Monitoring Report 2019") 2020.

[3] Fraunhofer Institute for Manufacturing Technology and Advanced Materials IFAM based on BDEW, ("Public charging points Germany“), 2013 bis 2019.

[4] J. van der Burgt, S. P. Vera, B. Wille-Haussmann, A. N. Andersen, and L. H. Tambjerg, "Grid impact of charging electric vehicles; study cases in Denmark, Germany and The Netherlands", 2015 IEEE Eind-hoven PowerTech, 2015.

[5] H. Wildemann: "Ladeinfrastruktur als Enabler der Elektromobilität" ("Charging infrastructure as enabler of electric mobility“), TCW Transfer-Centrum, 2018.

[6] electrive.net, eliso, "Marktübersicht AC- \& DC-Ladesäulen 2019" ("Market overview AC \& DC charging stations 2019"), June 2019.

[7] H. Engel, R. Hensley, S. Knupfer, S. Sahdev: "The potential impact of electric vehicles on global energy systems", McKinsey \& Company. [Online]. Available: https://www.mckinsey.com/industries/auto motive-andassembly/our-insights/the-potential-impact-of-electricvehicles-on-global-energy-systems.
[8] Chair and Institute of Urban and Transport Planning (ISB) of RWTH Aachen University, Project internal agreement, 2019

[9] A. Theißen: "SOC-Auswertung Projekt HansE" ("SOC Evaluation Project HansE"), Presentation, Chair and Institute of Urban and Transport Planning (ISB) of RWTH Aachen University, 2019.

[10] J. Figgener, D. Haberschusz, K.-P. Kairies, O. Wessels, B. Tepe, D. U. Sauer: "Wissenschaftliches Mess- und Evaluierungsprogramm Solarstromspeicher 2.0: Jahresbericht 2017" ("Scientific measurement and evaluation programme Solar Power Storage 2.0"), Annual Report 2017 Institute for Power Electronics and Electrical Drives of the RWTH Aachen University, 2017.

[11] A. A. K. Arani, H. Karami, G. B. Gharehpetian and M. S. A. Hejazi, "Review of Flywheel Energy Storage Systems structures and applications in power systems and microgrids", Renewable and Sustainable Energy Reviews, 69, pp. 9-18, 2017.

[12] A. F. Ghoniem, "Needs, resources and climate change: Clean and efficient conversion technologies", Progress in Energy and Combustion Science, 37(1), pp. 15-51, 2011.

[13] D. Bender, "Chapter 10 - Flywheels", in T. M. Letcher (ed.), Storing Energy With Special Relevance to Renewable Energy Sources, Elsevier, pp. 183-201, 2016. 